\title{
Preparation and In vitro Characterization of Aceclofenac Nanosuspension (ACNS) for Enhancement of Percutaneous Absorption using Hydrogel Dosage Form
}

\author{
Aseel Kadhem Thamer ${ }^{*}, 1$ and Ahmed Najim Abood ${ }^{* *}$ \\ *Basrah Health Directorate, Al-Fayhaa Teaching Hospital. \\ ** Department of Pharmaceutics, College of Pharmacy of Basrah, Basrah, Iraq.
}

\begin{abstract}
Aceclofenac (AC) is an orally active phenyl acetic acid derivative, non-steroidal anti-inflammatory drug with exceptional anti-inflammatory, analgesic and antipyretic properties. It has low aqueous solubility, leading to slow dissolution and inadequate bioavailability $(15 \%)$. The aim of the current study was to prepare and characterize AC-NS-based gel to enhance the dissolution rate and then percutaneous permeability. NS.s were prepared using solvent/antisovent precipitation method at different drug to polymer ratios $(1: 1,1: 2$, and 1:3) using poly vinyl pyrrolidone (PVP-K25), hydroxy propyl methyl cellulose (HPMC-E5) and poloxamer® (388) as stabilizers alone and in combinations of two polymers (1:2 and 1:4 drug: polymer ratio). Fifteen formulas of AC-NS.s were prepared and characterized for loading efficiency, particle size, polydispersity index and physical stability. The best formulas of NS were F11 (PVP K25, poloxamer® 338 and AC), and F15 (HPMC E5, poloxamer® 338 and AC) that gave the best results of physical stability and entrapment efficiency which were lyophilized to be characterized by FTIR, DSC, P-XRD and SEM. After that, the best prepared formula of AC-NS regarding the involved characterization methods was incorporated in gel dosage forms using ( $1 \% \mathrm{~W} / \mathrm{V}$ carbopol $\left.^{\circledR} 940\right)$. From this study, we conclude that the solubility and dissolution rate of $\mathrm{AC}$ were improved when the particle size was reduced to Nano-scale as compared with pure drug.
\end{abstract}

Keywords: Aceclofenac, Nanosuspension, Solvent/ antisolvent method, Hydrogel.

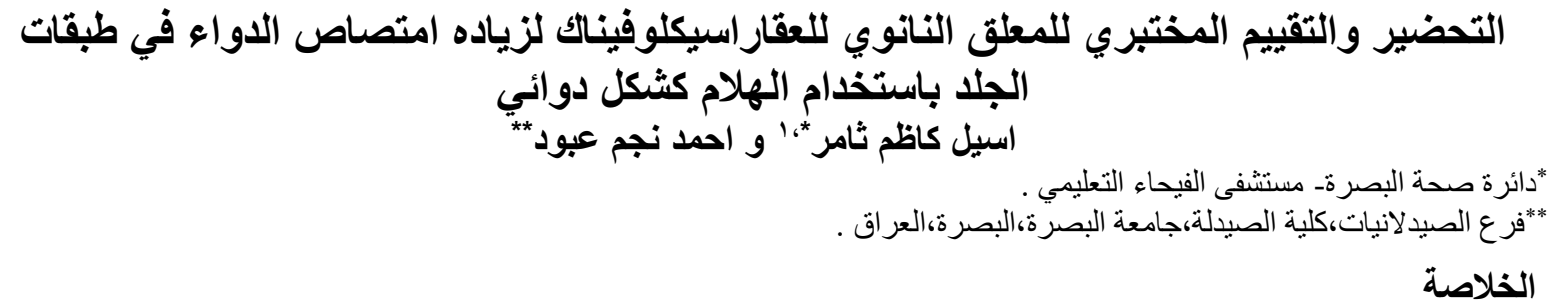

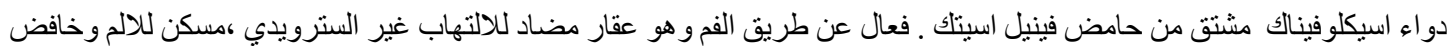

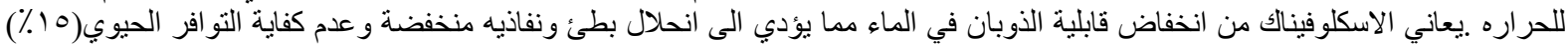

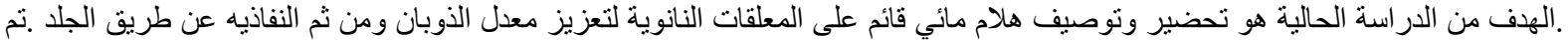

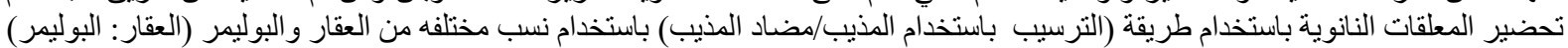

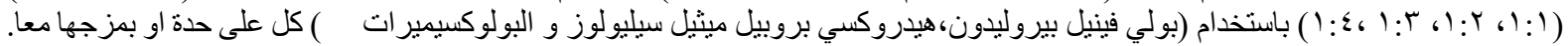

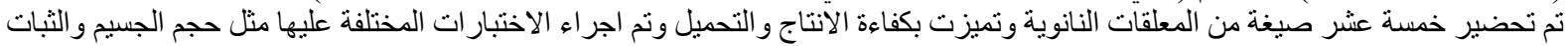

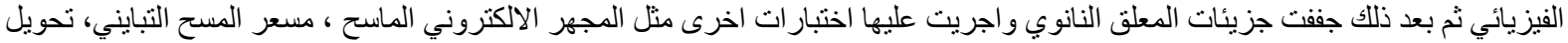

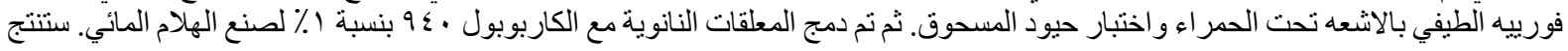

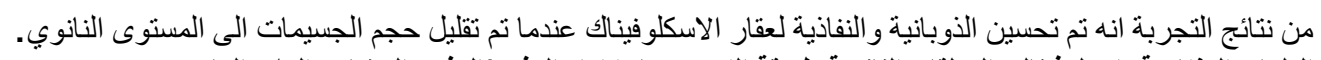

\section{Introduction}

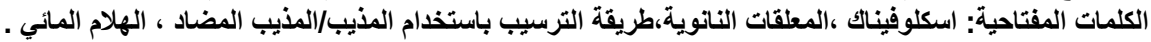

The word 'solubility' is defined as a maximum quantity of solute that can be dissolved in a given amount of solvent. There are various techniques for solubility enhancement like particle size reduction, solid dispersion, use of surfactants, pH modification, complexation, hydrotrophy, use of co-solvent and others ${ }^{(1)}$. When the particle becomes smaller, the surface area with volume ratio will be increases.

The large surface area enables greater contact with the solvent which lead to elevate solubility. Nanoparticles are particulate dispersions or solid particles with a size between $10-1000 \mathrm{~nm}^{(2)}$.

${ }^{1}$ Corresponding author E-mail: kadhemaseel@gmail.com

Received: 4/1/2021

Accepted: $1 / 3 / 2021$

Published Online First: 2021-12-09

Iraqi Journal of Pharmaceutical Science 
Nanoparticles stabilization is crucial to ensure their effectiveness. The massive rise in surface area causes excessive surface energy, which is undesirable thermodynamically. The increase in surface energy accelerates particle agglomeration to reduce over-energy on the surface. Agglomeration affects over all stability of the formulation of Nanoparticles ${ }^{3}$. Polymers like Poloxamers® (338), HPMC (E5), PVP (K25) and others provide stabilization for nanoparticles by surface binding as well as through the steric bulk of their threedimensional structure ${ }^{(4)}$.

$\mathrm{AC}$ is a non-steroidal anti-inflammatory drug, it is a phenyl acetic acid derivative (figure-1), white crystalline solid, almost insoluble in water and soluble in ethanol (96\%). After oral administration $\mathrm{AC}$ is absorbed and undergoes first pass hepatic metabolism ${ }^{(5)}$. It is recommended for the short and long term therapy of the signs and symptoms of rheumatoid arthritis, osteoarthritis and ankylosing spondylitis ${ }^{(6)}$.<smiles>O=C(O)COC(=O)Cc1ccccc1Nc1c(Cl)cccc1Cl</smiles>

Figure 1. Chemical structure of Aceclofenac (5)

Hydrogel is a water-swollen, cross-linked polymeric network formed by the simple reaction of one or more monomers ${ }^{(7)}$.

The main objective of this study is to modify AC particles to be prepared as NS using solvent/anti-solvent precipitation method and then incorporated in gel forming NS-based hydrogel type with improved dissolution rate and dermatological permeation.

\section{Materials and Methods \\ Materials}

Aceclofenac powder (AC), poloxamer® (338) were purchased from Lishui Nanming Chemical Co., Ltd (China). PVP®-K25, HPMC-E5 and carbopol ${ }^{\circledR} 940$ are gifts from Sama Alfayhaa for pharmaceutical industries. All other materials are of analytical grades.

Methods

\section{Characterization of aceclofenac powder Determination of melting point}

Melting point was determined by digital melting point apparatus. A few quantity of AC sample was taken and placed in a thin walled capillary tube which placed and heated in the device, when the sample start to melt, the melting point was recorded ${ }^{(8)}$.

\section{Spectrophotometric analysis}

AC powder (50mg) was weighed and dissolved in $(50 \mathrm{ml})$ of each of ethanol, phosphate buffer (pH 7.4) and DW (in presence of ethanol 1\% $(\mathrm{V} / \mathrm{V})$ as co-solvent $)^{9}$ to get stock solutions with concentrations $(1 \mathrm{mg} / \mathrm{ml})$. From which, serial dilutions were made and inspected spectrophotometrically. The $\lambda_{\max }$ values were determined and matched with literatures values ${ }^{(9)}$. The absorbance values of resultant diluted solutions were measured by UV-visible spectrophotometer using the respective blank solvents ${ }^{(10)}$.

\section{Determination of saturation solubility}

Excess amounts of AC powder were put in (25ml-conical flasks) containing $(20 \mathrm{ml})$ of each of the involved media as reported by Maulvi et al. After that, the conical flasks were shaken with orbital shaking incubator at $37 \pm 0.1^{\circ} \mathrm{C}$ for 24 hours, then kept in the incubator at $37^{\circ} \mathrm{C}$ for 24 hours until equilibrium existed, the supernatant solution filtered through a $0.45 \mu \mathrm{m}$ filter paper and analyzed spectrophotometrically, three determinations were carried out ${ }^{(11)}$.

\section{Preparation of AC-Nanosuspensions}

Solvent/anti-solvent precipitation process was used to prepare AC-NS. (100mg) of AC powder was dissolved in $2 \mathrm{ml}$ of ethanol, then added by syringe dropping into $(50 \mathrm{ml})$ of D.W. containing fixed quantities of one stabilizer or combinedstabilizers at room temperature and subsequently stirred by using magnetic stirrer at (800rpm) for (1hour) at $\left(40^{\circ} \mathrm{C}\right)$ to allow volatile solvents to evaporate ${ }^{(12)}$. The compositions of the prepared formulas (1-15) were illustrated in Table (1).

\section{Evaluation of the prepared AC-NS.s}

Measurement of particle size and polydispersity index (PDI)

Analysis of particle size was done using Malvern Mastersizer 2000 MS (Worcestershire, Great Britain). Average particle size and PDI of the prepared NS formulas were observed (The results of particle size was recorded as an average value depending on the device setting) to ensure that the particles are within Nano-range size and PDI is acceptable $^{(13)}$.

Measurement of \% entrapment efficiency (\%EE)

Freshly prepared drug-loaded NS.s were centrifuged at $12500 \mathrm{rpm}$ for 20 minutes. The concentration of drug in the supernatant was spectrophotometrically determined after filtration through $0.45 \mu \mathrm{m}$ filter paper at the estimated $\lambda_{\max }$. The EE of AC was calculated as follows ${ }^{(14)}$.

$\% \mathrm{EE}=\frac{\text { Wt intial drug }- \text { Wt free drug }}{\text { Wt intial drug }} \times \% 100$ 
Table 1. Compositions of AC NS.s formulas using different stabilizers at different drug: stabilizer ratios with constant volume of injected organic solution $(2 \mathrm{ml})$.

\begin{tabular}{|c|c|c|c|c||}
\hline $\begin{array}{c}\text { Formula } \\
\text { code }\end{array}$ & $\begin{array}{c}\text { Aceclofenac } \\
\text { amount } \\
(\mathbf{m g})\end{array}$ & $\begin{array}{c}\text { PVP K25 } \\
\text { Amount (mg) }\end{array}$ & $\begin{array}{c}\text { HPMC (E5) } \\
\text { Amount (mg) }\end{array}$ & $\begin{array}{c}\text { Poloxamer (338) } \\
\text { Amount (mg) }\end{array}$ \\
\hline F1 & 100 & 100 & & \\
\hline F2 & 100 & 200 & & \\
\hline F3 & 100 & 300 & 100 & \\
\hline F4 & 100 & & 200 & \\
\hline F5 & 100 & & 300 & 200 \\
\hline F6 & 100 & & & 100 \\
\hline F7 & 100 & & & 200 \\
\hline F8 & 100 & & & \\
\hline F9 & 100 & 100 & & \\
\hline F10 & 100 & 200 & 100 & \\
\hline F11 & 100 & 100 & & \\
\hline F12 & 100 & 200 & & \\
\hline F13 & 100 & & & \\
\hline
\end{tabular}

\section{Physical stability assessment}

The prepared NS formulas were stored in a dark place at an ambient temperature for up to seven days. During this time, the particle size and visual appearance were monitored and determined ${ }^{(15)}$.

Lyophilization of the prepared NS formulas

For further characterization, the best formulas were lyophilized using freeze dryer (Labconco USA). The powder yields were kept in a tight container at room temperature ${ }^{(16)}$.

\section{Characterization of the lyophilized powder}

Scanning electron microscopy (SEM) analysis

The particle morphology of lyophilized powder and unprocessed drug were characterized by using SEM. A small fraction was fixed on a doublesided conductive carbon tape and sputter-coated with $5 \mathrm{~nm}$ of a Pt-Pd alloy ${ }^{(17)}$.

\section{Compatibility studies}

\section{Differential scanning calorimetry (DSC)}

This test was used to examine the physical compatibility between AC, additives and methods conditions. The samples were precisely weighed and sealed hermetically with aluminum lid. The thermograms of lyophilized AC formulas and pure drug powder were recorded ${ }^{(18)}$.

\section{Fourier transform infrared spectroscopy (FTIR)}

FTIR scanning of $\mathrm{KBr}$ pellets containing powder samples of pure drug, lyophilized formulas in the wave number range $400-4000 \mathrm{~cm}^{-1}$ at a resolution of $4 \mathrm{~cm}^{-1}$ with speed of $2 \mathrm{~mm} / \mathrm{sec}^{(19)}$,

\section{Powder x-ray diffraction (PXRD)}

Using a Diano X-ray diffractometer (USA) equipped with Co-K $\alpha$ radiation $(45 \mathrm{kV}, 9 \mathrm{~mA}$, scanned from $3^{\circ}$ to $50^{\circ}$ at 2 angles), samples from pure drug and lyophilized formulas powders were analyzed $^{(20)}$.

\section{Preparation of NS-based hydrogel}

Carbopol ${ }^{\circledR} 940$ was used as gelling agent in concentration of (1\%) to prepare NS-based hydrogel from the selected AC-NS formula. The calculated amount of carbopol was dispersed in water using a magnetic stirrer with a speed of (1000 rpm) for (1 hour) until getting uniform dispersion, then a freshly prepared AC-NS formula (the selected one) was gradually added to the aqueous dispersion of carbopol. After that (1.6) ml glycerin was added as a viscosity modifier. Finally, few drops of triethanolamine were added to initiate the hydrogel formation (21). The prepared hydrogel had been allowed to stand overnight to clear stuck air, then the prepared hydrogel formula was sealed in a tightly closed container at room temperature in a dark place for other tests (22). Additionally, by the same procedure, plain hydrogel was prepared using AC pure form.

\section{Evaluation of the prepared hydrogel \\ Measurement of $\mathrm{pH}$}

The $\mathrm{pH}$ of the prepared hydrogel formula was determined using a $\mathrm{pH}$ meter at room temperature. This was done by fully placing the glass electrode in the gel system and recording $\mathrm{pH}$ (23).

\section{Spreadability}

Hydrogel formulas were found to be spreadable or not after (48 hour) of preparation, by measuring 2 $\mathrm{g}$ of gel spreading-diameter between two (10X10 $\mathrm{cm})$ glass plates. Determination of diameter after 1 minute of applying the weight. The spreadability can be calculated using the following equation: 
$\mathbf{S}=\mathbf{m} . \mathbf{l} / \mathbf{t}$

Where: $\mathrm{S}$ is spreadability, $\mathrm{m}$ is the weight tied to the upper slide, 1 is the length of the glass slide and $t$ is time consumed ${ }^{(24)}$.

\section{Rheological studies (Viscosity analysis)}

They were done by Drawell NDJ-8S viscometer. The hydrogel was filled in a wide mouth container, so that the viscometer's spindle could be appropriately dipped without touching the bottom of jar. Hydrogel samples were permitted to settle at constant temperature more than 30min. The viscosity was measured by increasing the speed of rotation starting from $0.3 \mathrm{rpm}$ to $60 \mathrm{rpm}$. This done by using a spindle (number 4 ). The measurements were recorded at temperature of $25^{\circ} \mathrm{C}^{(25)}$.

\section{In vitro drug release study}

The NS-based hydrogel release analysis was performed by using assembly franze diffusion cell ${ }^{26}$ using a tube in which one end covered by dialysis membrane (8000-14000 Dalton cut-off) that is soaked in a freshly prepared diffusion medium (phosphate buffer $\mathrm{pH}$ 7.4) over night. A specific amount of hydrogel equivalent to $(100 \mathrm{mg})$ of $\mathrm{AC}$ was taken and spread on a semi-permeable dialysis membrane, the tube was partially submerged in a jar containing buffer. The temperature was held at $32 \pm$ $0.5{ }^{\circ} \mathrm{C}$ stirred at $100 \mathrm{rpm}$. Two milliliters-sample was taken at different time intervals and the drug concentration was spectrophotometrically determined at the determined $\lambda_{\max }$ against a suitable blank ${ }^{(27)}$.

The obtained data were fitted to different mathematical expressions to describe the kinetic and mechanism of aceclofenac release from the selected nanosuspension formulas with the help of DDSolver: An add-in program in Microsoft Excel (28). The kinetic models (zero order, first order, Higuchi model and Korsmeyer - Peppas) were used $^{29}$. The model that produced the highest correlation coefficient was selected as the best fitted model.

\section{Stability studies (Effect of temperature)}

For the assessment of the stability, the prepared hydrogel formula was kept at different temperature degrees: a refrigerator $\left(4^{\circ} \mathrm{C}\right)$, oven $(40$ $\left.{ }^{\circ} \mathrm{C}\right)$ and room temperature $\left(25^{\circ} \mathrm{C}\right)$ for three months. Samples were periodically withdrawn and tested for the physical appearance, homogeneity and viscosity ${ }^{(30)}$.

\section{Statistical analysis}

The results of particle size was recorded as an average value depending on the device setting, while others have been mostly provided as the mean value of triplicate readings \pm standard deviation and have been assayed statistically using (ANOVA) test for estimation if changes of involved variables have been statistically significant at level $(\mathrm{P} \leq 0.05)$ and non-significant at level of ( $p>0.05)$.

\section{Results and Discussion Determination of melting point}

It was found to be $\left(156-158^{\circ} \mathrm{C}\right)$ which is the same as reported reflecting the purity of the powder used in the study ${ }^{(31)}$.

\section{Spectrophotometric analysis}

The estimated $\lambda_{\max }$ is $275 \mathrm{~nm}$ that is agreed with the reported values ${ }^{(32)}$. Figures (2-A, 2-B and $2-C)$ showed the calibration curves in the involved media. A straight lines were obtained indicating that the calibration curves obeys Beer-lambert law within the range of concentrations used ${ }^{(33)}$.

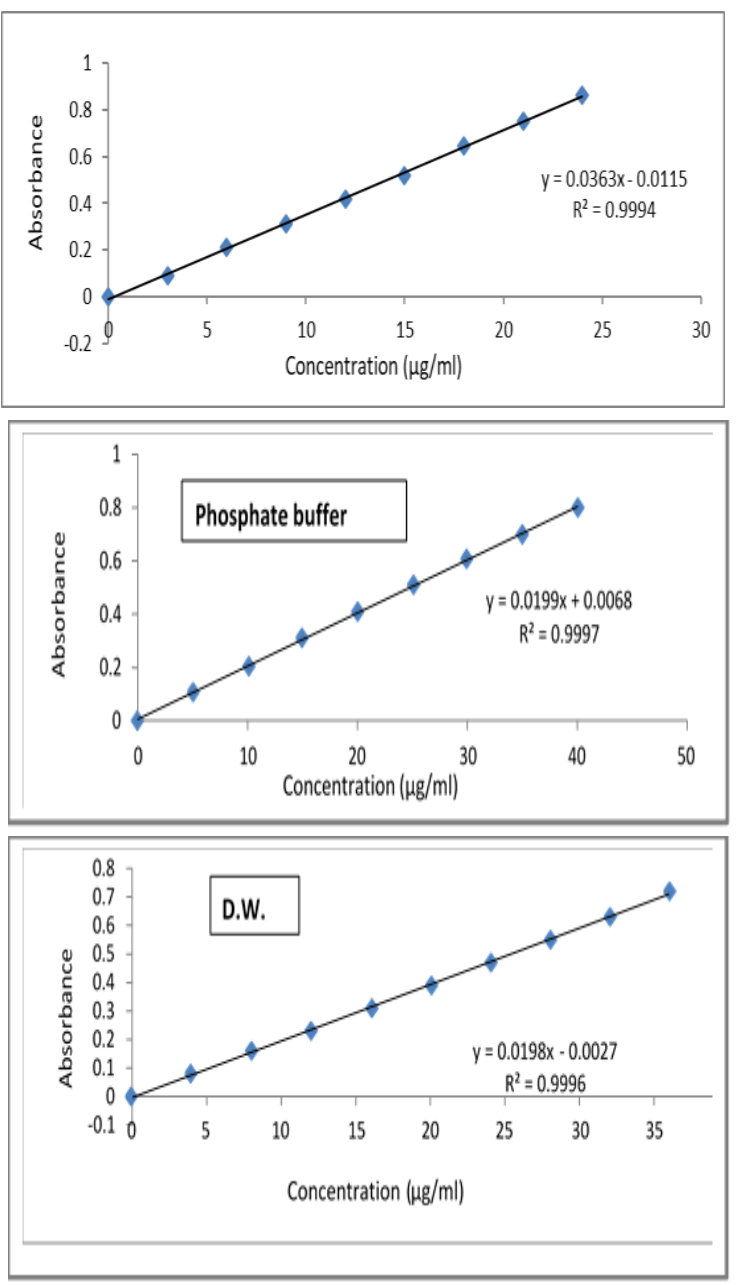

Figure 2. Calibration curves of $\mathrm{AC}$ in ethanol, phosphate buffer pH 7.4 and D.W.

\section{Saturated solubility of AC powder}

The saturation solubility values of $\mathrm{AC}$ at different media were summarized in Table (2). From which, we conclude that AC is practically insoluble 
in water and soluble in ethanol ${ }^{34}$. The aqueous solubility will be increased by increasing $\mathrm{pH}$ due to weakly acidic properties of drug as in phosphate buffer medium $\mathrm{pH} 7.4^{(35)}$.

Table 2. Solubility of $\mathrm{AC}$ at $37 \pm 0.1^{\circ} \mathrm{C}$ in different media $(n=3)$

\begin{tabular}{||c|c||}
\hline \hline Media & $\begin{array}{c}\text { Saturation solubility } \\
(\mathrm{mg} / \mathrm{ml}) \pm \text { SD }\end{array}$ \\
\hline D.W & $0.07 \pm 0.01$ \\
\hline Phosphate buffer 7.4 & $14.2 \pm 0.04$ \\
\hline Ethanol & $40 \pm 0.02$ \\
\hline
\end{tabular}

\section{Preparation of $A C-N S$}

In this study, fifteen formulas of AC-NS.s were prepared having particle size values within nanometer range as illustrated in Tables (3 and 4) which are exposed for several characterization methods to get the best one.

Table 3. Particle size, polydispersity index values of the prepared formulas using different types and amount of single stabilizer

\begin{tabular}{||c|c|c||}
\hline $\begin{array}{c}\text { Formula } \\
\text { code }\end{array}$ & $\begin{array}{c}\text { Average particle size } \\
\text { (nm) }\end{array}$ & PDI \\
\hline F1 & 270 & 0.3 \\
\hline F2 & 202 & 0.3 \\
\hline F3 & 164 & 0.3 \\
\hline F4 & 198 & 0.09 \\
\hline F5 & 271 & 0.07 \\
\hline F6 & 220 & 0.07 \\
\hline F7 & 98 & 0.3 \\
\hline F8 & 112 & 0.3 \\
\hline F9 & 85 & 0.3 \\
\hline
\end{tabular}

Table 4.Particle size and PDI values for the prepared formulas (using combined stabilizers)

\begin{tabular}{||c|c|c||}
\hline Formula code & $\begin{array}{c}\text { Average Particle } \\
\text { size (nm) }\end{array}$ & PDI \\
\hline F10 & 72 & 0.09 \\
\hline F11 & $\mathbf{4 3}$ & $\mathbf{0 . 0 6}$ \\
\hline F12 & 242 & 0.1 \\
\hline F13 & 237 & 0.07 \\
\hline F14 & 41 & 0.1 \\
\hline F15 & $\mathbf{4 5}$ & $\mathbf{0 . 0 9}$ \\
\hline
\end{tabular}

\section{Characterization of the prepared AC-NS formulas Particle size and PDI measurements}

The most important characterization parameters for the prepared NS.s are the average particle size and PDI which governs the physicochemical properties like saturation solubility, dissolution velocity and physical stability (36). The usual range of PDI obtained values are (0.10.25 ) which indicates narrow size distribution while PDI value more than 0.5 refer to very broad distribution (37). The PDI values of prepared formulas were ranged from $(0.06-0.3)$. The best formulas (F11 and F15) have Nano-sized particle with low PDI values (0.06 and 0.09) respectively as shown in Table (4) which indicates good uniformity of nanoparticles.

Stabilizers such as HPMC, PVP and poloxamer were incorporated to prevent sedimentation, agglomeration and crystal formation (38). In addition to the safety and regulatory requirements, the choice of stabilizer is based on their ability to provide particle surface wetting and a barrier to prevent agglomeration of nanoparticles. Formulas (F1-F3) give a good average particle size especially at drug: polymer ratio (1:3) with remarkable increase in average particle size, this may be due to role of PVP in inhibiting guest molecule crystallization and its excellent efficiency as agent for coating and high affinity of polymer to the nanoparticals surface ${ }^{(39)}$.

Formulas F4-F6, also give a good average particle size with increase in size when changing the concentration of the polymer reaching to drug: polymer ratio (1:3). This is attributed to the fact, HPMC has both a hydrophobic alkyl chain and hydrophilic $\mathrm{OH}^{-}$in its side chain. On the Nano crystalline surface, the hydrophobic alkyl chain can be adsorbed, while the hydrophilic $\mathrm{OH}^{-}$groups are exposed to increase the wettability of the Nano crystals ${ }^{(40)}$. Formulas F7-F9 had the best average size, at drug: polymer ratio $1: 3$, it gave $(85 \mathrm{~nm})$ size, this because of its high molecular weight and a greater polypropylene oxide (PPO) region of poloxamer. Therefore, because of adsorption occurs via this hydrophobic PPO block, it has more 'anchoring capacity' to the nanoparticle surface ${ }^{(41)}$. Optimum stabilizer concentration is needed where the use of insufficient amount of stabilizer may not provide complete coverage of the drug surface, thus jeopardizing steric repulsion between particles ${ }^{(42)}$.

In our study, we see that as the concentration of stabilizer increases, the average particle size was decreased as seen in Table (3) in which the formulas coded (F3 and F9) give smaller particle sizes (164 and $85 \mathrm{~nm}$ ) respectively at which highest amount of polymers use. According to the above result a smaller particle size $(85 \mathrm{~nm})$ was seen when using poloxamer 338 in higher amount, since this polymer show reduction in average particle size because of the high molecular weight of polymer.

Smaller average particle size values were obtained for F11 about (43 nm) and F15 about (45 
nm) when using combination of (PVP K25 + Poloxamer 338) and (HPMC + Poloxamer 338) respectively at ratio of ( 1 drug: 4 polymer) as shown in Table (4). So these combinations showed a significant reduction in the average particle size $(\mathrm{p}<$ 0.05). Also these formulas (F11 and F15) have PDI values (0.06 and 0.09$)$ respectively which indicates a good polydispersity. These results may be obtained because of an excellent surface affinity of stabilizers toward drug molecules forming a large mechanical and thermodynamic barrier at the interface ${ }^{(43)}$. The ratio of drug to polymer $(1: 4)$ looked to be optimum due to the effect of amount of polymer on the properties of the nanoparticles. The reason may be due to the fact, the viscous polymer solution has more difficulty to break up into smaller droplets at the same mixing input strength, leading to a rise in particle size ${ }^{(44)}$.

\section{Determination of \%EE}

The $\% \mathrm{EE}$ values of the prepared formulas were ranged from $86.3(\mathrm{~F} 9)$ to $94.2 \%(\mathrm{~F} 15)$ as showed in Table (5). There is no significant difference ( $p>0.05$ ) between the prepared AC-NS.s which may give an impression of suitability of stabilizer mechanism (steric stabilization) especially when used in combination that give synergistic effect for stabilization of AC nanoparticles ${ }^{44}$. It is clear that the increase in stabilizer concentration can increase the $\% \mathrm{EE}$, but the study revealed that the concentration of stabilizers at ratio (1 drug: 4 stabilizer) was sufficient to give the optimized \%EE. This may be due to the presence of optimum stabilizer type and optimum stabilizer concentration (45).

Table 5. EE values of the prepared formulas $(\mathbf{n}=3)$

\begin{tabular}{|c|c|}
\hline Formula code & EE\% \pm SD \\
\hline F1 & $90.2 \pm 0.06$ \\
\hline F2 & $92.4 \pm 0.03$ \\
\hline F3 & $92.6 \pm 0.04$ \\
\hline F4 & $87.6 \pm 0.01$ \\
\hline F5 & $90 \pm 0.1$ \\
\hline F6 & $92.3 \pm 0.11$ \\
\hline F7 & $86.3 \pm 0.1$ \\
\hline F8 & $90.2 \pm 0.08$ \\
\hline F9 & $93.5 \pm 0.06$ \\
\hline F10 & $89.4 \pm 0.005$ \\
\hline F11 & $92.7 \pm 0.01$ \\
\hline F12 & $86.4 \pm 0.01$ \\
\hline F13 & $93.5 \pm 0.17$ \\
\hline F14 & $91.2 \pm 0.02$ \\
\hline F15 & $97.5 \pm 0.05$ \\
\hline
\end{tabular}

\section{Physical stability of AC-NS}

The prepared formulas were tested for their physical stabilities for one weak at ambient temprature. Formulas F11 and F15 were seemed to be clear after ( 1 weak) as seen in Table(6). Other formulas look to be precipitated due to increase particle size. The improved stability may be due to the increased thickness of layer of adsorbed polymer when Poloxamer 338, HPMC E5 and PVP K25 were used in combinations, thus preventing the particles from aggregation and/or agglomeration by providing steric hindrance. NS stabilization can be done by electrostatic, steric, or electrostatic modulation (a combination of them) ${ }^{(46)}$.

Table 6. Physical stability study for F11 and F15 formulas

\begin{tabular}{|c|c|c||}
\hline $\begin{array}{c}\text { Measurement } \\
\text { time }\end{array}$ & $\begin{array}{c}\text { F11 } \\
\text { (Particle } \\
\text { size in } \text { nm) }\end{array}$ & $\begin{array}{c}\text { F15 } \\
\text { (Particle } \\
\text { size in nm) }\end{array}$ \\
\hline Initial time & $\mathbf{4 3}$ & 45 \\
\hline $2^{\text {nd }}$ day & $\mathbf{5 0}$ & 54 \\
\hline $7^{\text {th }}$ day & $\mathbf{6 7}$ & 80.2 \\
\hline
\end{tabular}

\section{Characterization of the lyophilized powder SEM}

The morphological analysis and particle size values of (F11 and F15) in compare to AC row powder were performed by SEM showing nanoparticles with a size of (43 and $45 \mathrm{~nm}$ ) as seen in figure (5). No aggregation of particles could be observed.

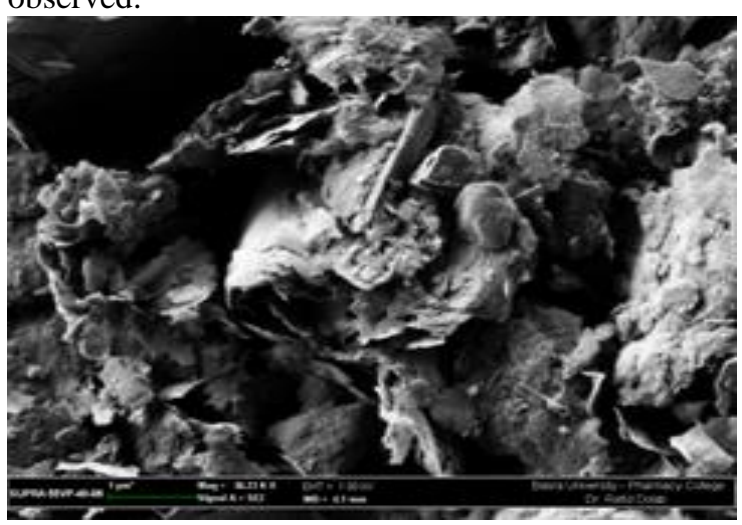

A

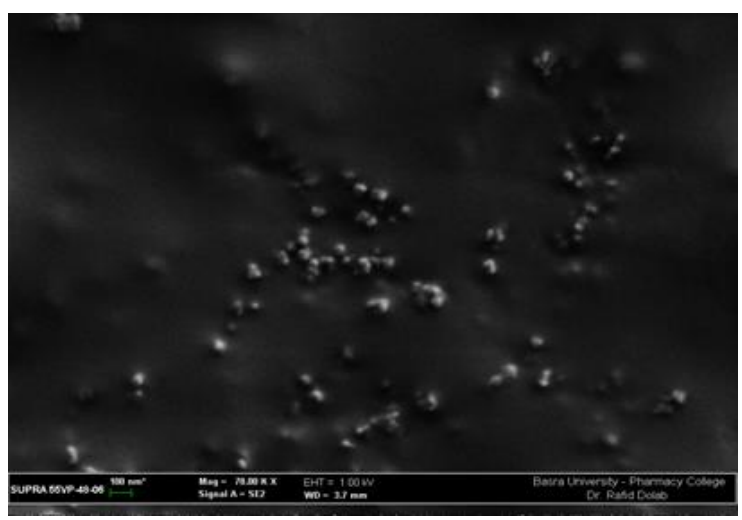

B 


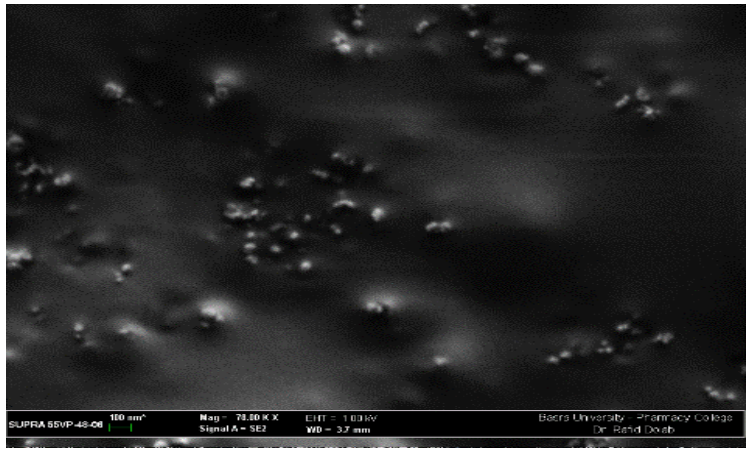

C

Figure 5. SEM micrograph for pure AC powder at 36.23 KX magnification (A), lyophilized F11 at 78.00 KX magnification (B) and lyophilized F15 at 78.00 KX magnification (C).

\section{DSC}

DSC thermogram of pure AC powder \{figure (6-A) \} showed a sharp characteristic endothermic peak at $\left(156.30^{\circ} \mathrm{C}\right)$ that is agreed with references. This gives an indication that the drug has crystalline nature with high purity. The DSC thermograms of the lyophilized formulas (figure (6-F11)) was showed shifting of the peak while figure (6-F15) showed loss of the melting endotherm which may be due to presence of small quantity of aceclofenac. Changing in the peak was reflecting the changing in the crystalline state of aceclofenac to amorphous ${ }^{(47,}$ 48).
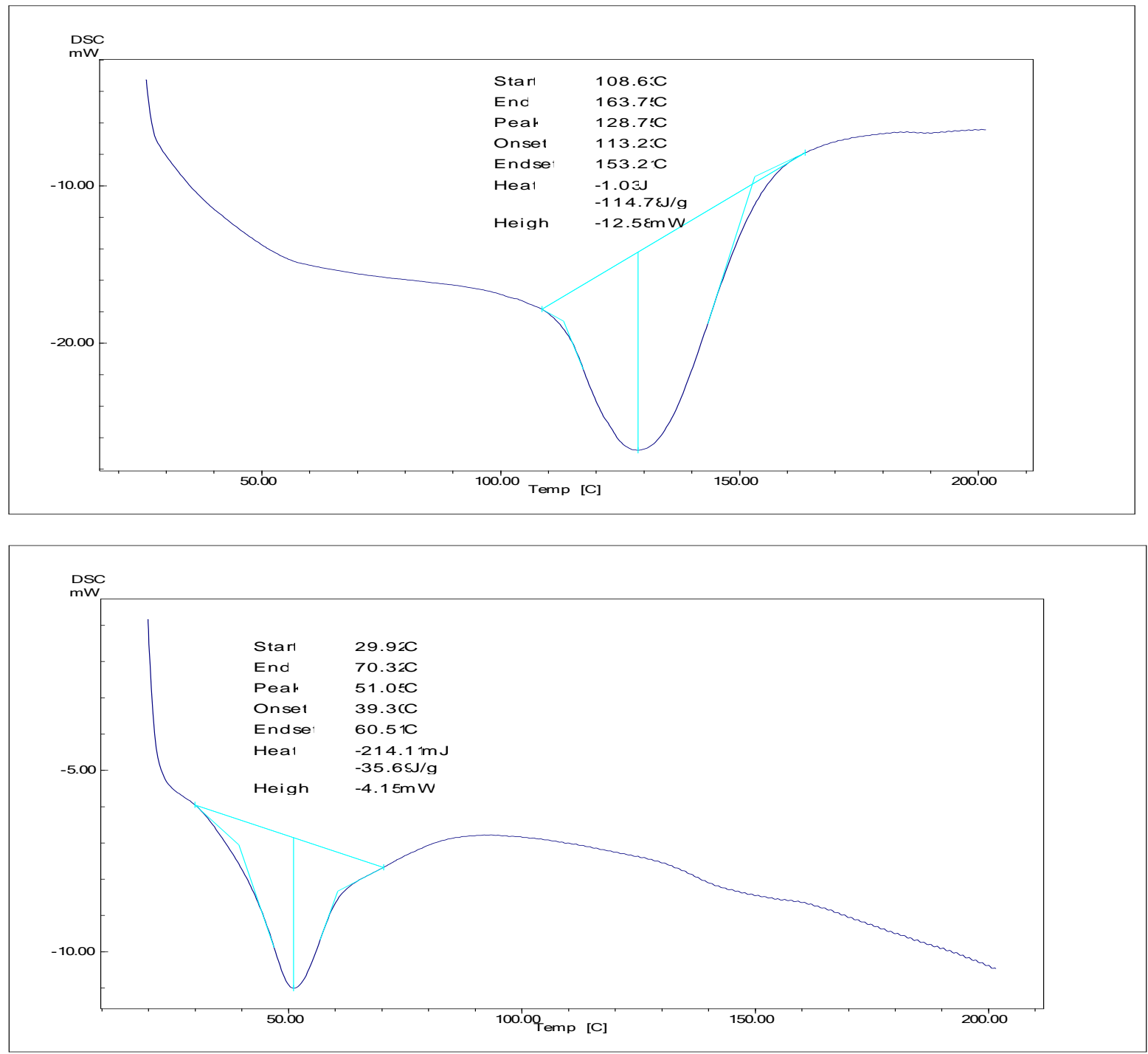

Figure 6. DSC thermograms of pure AC powder, F11 and F15. 


\section{FTIR spectra}

The characteristics absorption bands of AC were: $3318 \mathrm{~cm}^{-1}(\mathrm{~N}-\mathrm{H}$ stretching or $\mathrm{O}-\mathrm{H}$ stretching), 3277 and $2936 \mathrm{~cm}^{-1}$ (C-H stretching) due to both aromatic and aliphatic stretching vibrations respectively in addition to $1771 \mathrm{~cm}^{-1}(-\mathrm{C}=\mathrm{O}$ stretching), 1585 and $1506 \mathrm{~cm}^{-1}(-\mathrm{C}=\mathrm{C}$ stretching of aromatic), and some prominent bands as explained in figure (7).
The spectrum of lyophilized powder showed the same characteristic peaks, albeit of smaller intensity as seen in figure (7). The results showed no major differences in the peaks of AC relative to the pure drug in the prepared formulas, suggesting the absence of any interaction between drug and polymers. A broad peak may be attributed to hydrogen bond between drug and polymer ${ }^{(49)}$.
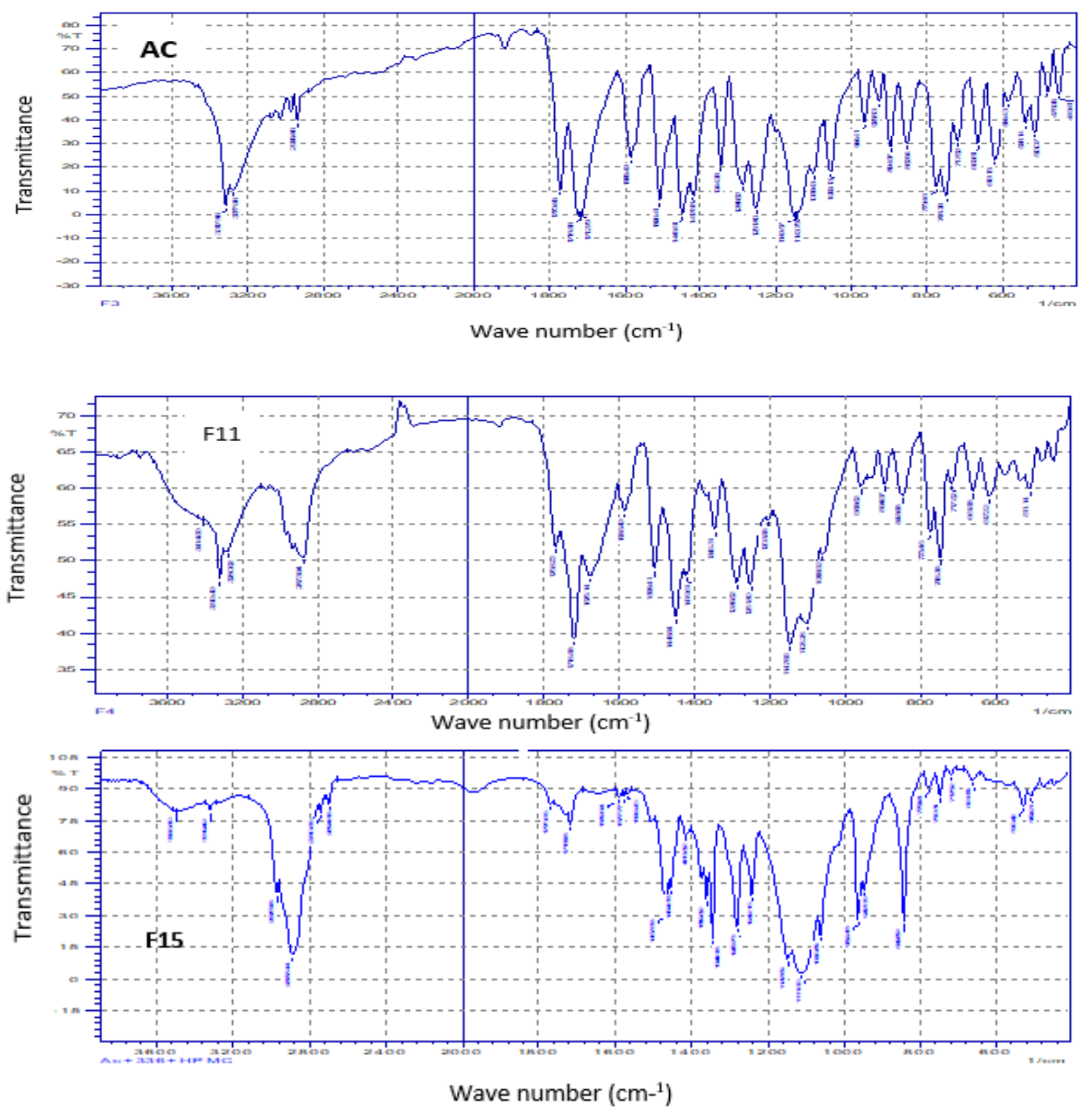

Figure 7. FTIR spectra for pure AC powder, F11 and F15. 


\section{PXRD}

PXRD assays were done for pure drug and the lyophilized formulas as showed in figure (8). The PXRD patterns of AC pure drug showed a sharp diffraction peaks indicating the crystalline nature of the drug as a consequence of different arrangement of the molecules in the crystal lattice.

In the lyophilized formulas, lack of distinctive drug peaks or a significant reduction in the characteristic peaks indicating that $\mathrm{AC}$ was trapped in an amorphous or molecular shape within the mixture, this is agreed with the results obtained from the DSC assay ${ }^{(50)}$.
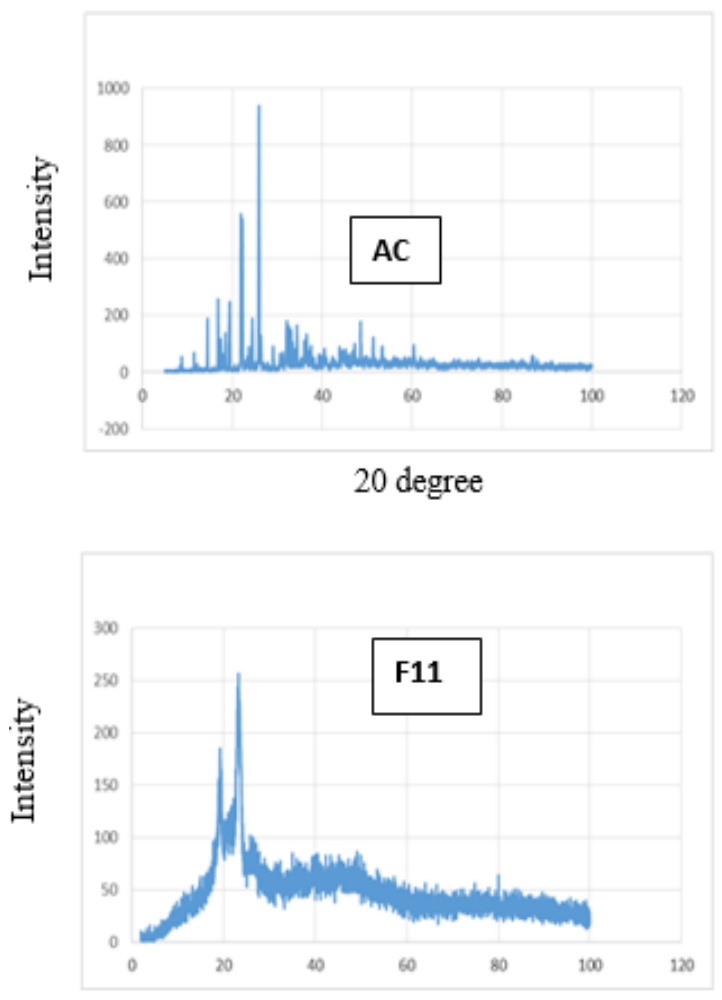

20 degree

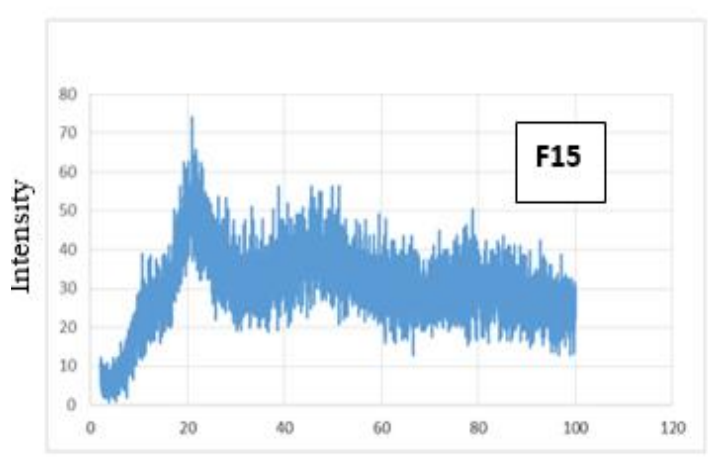

20 degree

Figure 8. PXRD graphs for AC powder, F11 and F15

\section{Preparation of hydrogel}

F15 was selected to be incorporated in hydrogel system. For comparison, blank hydrogel containing unprocessed AC powder was also prepared.

\section{Characterization of NS based-hydrogel \\ Physical appearance}

Visual inspection of the prepared AC-NS based- hydrogel revealing a good homogeneity, free of grittiness and no phase separation. The gel of F15 with carbopol concentration (1\%) was appeared to be white in appearance.

\section{pH determination}

The $\mathrm{pH}$ values of the prepared $\mathrm{AC}$ hydrogels were (6.83 to 6.87) as seen in Table (7).

Table 7.Spread-ability and $\mathrm{pH}$ values of the prepared aceclofenac hydrogels $(n=3)$

\begin{tabular}{||c|c|c|}
\hline $\begin{array}{c}\text { Formula } \\
\text { number }\end{array}$ & $\begin{array}{c}\text { spreadability } \\
(\text { g.cm2/sec }) \pm \text { SD }\end{array}$ & PH \pm SD \\
\hline F15 & $14.3 \pm 0.01$ & $6.83 \pm 0.02$ \\
\hline blank & $10.6 \pm 0.015$ & $6.87 \pm 0.025$ \\
\hline
\end{tabular}

\section{Spread-ability measurement}

The prepared hydrogel was easily spreadable by applying little shear as seen in Table (7). Good spread-ability value is one of the essential properties for gel dosage form. Spread-ability suggests gel propagation capability to a part of the skin. The therapeutic efficiency of gel determined according to spreading value ${ }^{(51,52)}$.

\section{Determination of the viscosity}

The viscosity was measured at different shear rates and the data are represented in Table (8). It can be seen in (figure-9) that the viscosity of hydrogel of F15 was ranged (180456-11306 cp), while for the blank hydrogel is (168435-10524cp). It was found that as the shear rate increased as the viscosity was decreased. Therefore, it is a nonNewtonian flow behavior ${ }^{(53)}$. The results showed that carbopol was a good gelling agent for preparation of hydrogels. 
Table 8.Viscosity values for the prepared AC hydrogels

\begin{tabular}{||c|c|c|c||}
\hline $\begin{array}{c}\text { Speed } \\
(\text { rpm })\end{array}$ & $\begin{array}{c}\text { shear } \\
\text { rate } \\
(1 / \text { sec. })\end{array}$ & $\begin{array}{c}\text { Gelled F15 } \\
\text { viscosity } \\
(\text { cp })\end{array}$ & $\begin{array}{c}\text { Blank } \\
\text { hydrogel } \\
\text { viscosity } \\
\text { (cp) }\end{array}$ \\
\hline 1.5 & 0.32 & 178456 & 168435 \\
\hline 2 & 0.41 & 140786 & 138576 \\
\hline 2.5 & 0.49 & 99800 & 95723 \\
\hline 3 & 0.6 & 83350 & 80836 \\
\hline 6 & 1.32 & 60566 & 58243 \\
\hline 12 & 2.48 & 48270 & 46387 \\
\hline 30 & 6.4 & 24546 & 27534 \\
\hline 60 & 13.16 & 13785 & 10524 \\
\hline
\end{tabular}

\section{Determination of the viscosity}

The viscosity was measured at different shear rates and the data are represented in Table (8). It can be seen in (figure-9) that the viscosity of hydrogel of F15 was ranged (180456-11306 cp), while for the blank hydrogel is (168435-10524cp). It was found that as the shear rate increased as the viscosity was decreased. Therefore, it is a nonNewtonian flow behavior ${ }^{(53)}$. The results showed that carbopol was a good gelling agent for preparation of hydrogels.

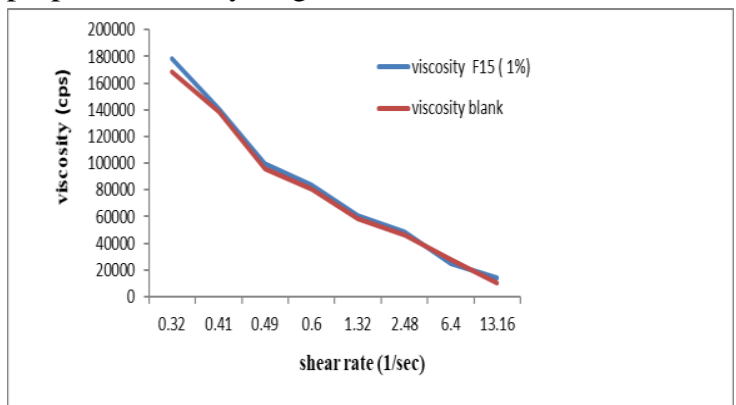

Figure 9.Viscosity versus shear rate for gelled F15 and the blank hydrogel.

\section{In vitro drug release study}

In vitro drug release study was done in phosphate buffer ( $\mathrm{pH}$ 7.4). Figure (10) showed the release pattern of drug from the prepared hydrogels. At 10 hour period of the release assay, the cumulative percentages of drug release were in the order: gel of F15> plain hydrogel with $84.8 \%$ and $32.6 \%$ respectively. At $12 \mathrm{hr}$., the release of gel F15 reached to $100 \%$, while plain hydrogel had the lowest release percentage, as we see there was a significant difference $(\mathrm{p}<0.05)$ between F15 hydrogel and plain hydrogel, this is due to improved dissolution rate and permeation due to small size of nanoparticles, i.e. the reduction in particle size leading to increased dissolution velocity. As drug particles are smaller, the corresponding surface area is greater, according to the Noyes-Whitney equation, so the nanocrystals have a significant elevation area. In addition, the diffusion distance decreases for very small particles. The increased surface area and the simultaneous decrease in diffusion distance could therefore significantly increase the velocity of dissolution of the substance (54).

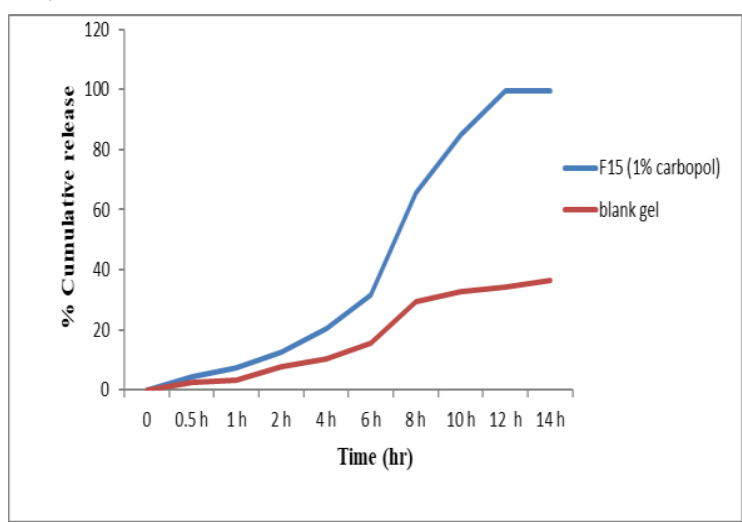

Figure 10. The cumulative release of $\mathrm{AC}$ for gelled F15 and blank hydrogel

The release of AC from hydrogel of F15 is best fit with higher correlation $\left(\mathrm{R}^{2}\right)$ with zero order equation which show zero order release profile. While the blank hydrogel $\left(\mathrm{R}^{2}=0.969\right)$ fitted with first order kinetics. It is worth mentioning that the diffusional exponent (n) obtained from KorsmeyerPeppas can be utilized by calculating $60 \%$ release of the drug. When the liquid diffusion rate is slower than the relaxation rate of the polymeric chains, the diffusion is Fickian or called case-I transport ( $\mathrm{n} \leq$ 0.5 ). When liquid diffusion rate and polymer relaxation rate are of the same order of magnitude, non-Fickian diffusion or anomalous transport $(0.5<$ $\mathrm{n}<1)$ is observed. When liquid diffusion rate and polymer relaxation rate are of the same time but diffusion rate more than relaxation rate are, super case - II transport $(n>1.0)$ is observed. While the relaxation process is very slow compared with the diffusion, the case - II transport occurs (Zero order kinetic model) ${ }^{(29)}$.

The value of (n) for hydrogel of F15 (1\%) was (0.822) and blank hydrogel was (0.873) that both of them were $>0.5$ and $<1$ which indicates that the drug release mechanism was non Fickian, and suppose that aceclofenac hydrogel delivered their 
active ingredients by non Fickian diffusion (see Table 9).

Table 9. In vitro release kinetics of $\mathrm{AC}$ hydrogel formulas

\begin{tabular}{||c|c|c|c|c||}
\hline $\begin{array}{c}\text { Formul } \\
\text { a code }\end{array}$ & $\begin{array}{c}\text { zero } \\
\text { orde } \\
\mathbf{r ~ R}^{\mathbf{2}}\end{array}$ & $\begin{array}{c}\text { first } \\
\text { orde } \\
\mathbf{r ~ R}^{\mathbf{2}}\end{array}$ & $\begin{array}{c}\text { higuch } \\
\mathbf{i} \mathbf{R}^{\mathbf{2}}\end{array}$ & $\begin{array}{c}\text { kosmeyer } \\
\text {-peppas } \\
\text { (n) }\end{array}$ \\
\hline 15 & 0.974 & 0.943 & 0.917 & 0.822 \\
\hline blank & 0.951 & 0.969 & 0.88 & 0.873 \\
\hline
\end{tabular}

Stability test

The results of stability test were illustrated in Table (10). The drug content was reduced at elevated temperature and this can be diminish by storage in refrigerator ${ }^{(55)}$.

Table 10. Stability tests of gelled F15 $(n=3)$

\begin{tabular}{|c|c|c|c||}
\hline $\begin{array}{c}\text { Stability } \\
\text { paramet } \\
\text { er }\end{array}$ & $\mathbf{2 5}^{\circ} \mathbf{C}$ & $\mathbf{4 0}^{\circ} \mathbf{C}$ & $\mathbf{4}^{\circ} \mathbf{C}$ \\
\hline $\begin{array}{c}\text { appearan } \\
\text { ce }\end{array}$ & $\begin{array}{c}\text { homogen } \\
\text { ous }\end{array}$ & $\begin{array}{c}\text { homogen } \\
\text { ous }\end{array}$ & $\begin{array}{c}\text { homogen } \\
\text { ous }\end{array}$ \\
\hline $\begin{array}{c}\mathrm{pH} \pm \text { SD } \\
\text { Drug } \\
\text { content } \\
\pm \text { SD }\end{array}$ & $\begin{array}{c}97.5 \pm 0.05 \\
1\end{array}$ & $\begin{array}{c}66.43 \pm 0.0 \\
15\end{array}$ & $97.5 \pm 0.01$ \\
\hline
\end{tabular}

\section{Conclusions}

AC-NS.s have been successfully prepared using various stabilizers in different stabilizer: drugs ratios $(1: 1,2: 1,3: 1$ and $4: 1)$. The data indicate that the process of solvent/anti-solvent precipitation is an efficient and a cost-effective method for preparing drug NS.s, and easily to implement for the manufacturing of drug nanoparticles. The results confirm that when AC particles are Nano sized, both the solubility and dissolution are improved. AC-NS based hydrogel showed enhanced release rate of drug as compared with blank hydrogel.

\section{Acknowledgments}

I would like to thank College of pharmacy of Basrah and all the staff of the Department of Pharmaceutics, and especially Assistant lecturer Noor Yousif. My deep thanks to Sama Al fayhaa pharmaceutical industry and pioneer pharmaceutical company for their generous supply with some of the needed chemicals.

\section{References}

1. Savjani KT, Gajjar AK, Savjani JK. Drug Solubility: Importance and Enhancement
Techniques. ISRN Pharm. 2012;2012(100 $\mathrm{mL}): 1-10$.

2. Mohanraj VJ, Chen Y., Nanoparticles - A review. Trop J Pharm Res. 2007;5(1):561-573.

3. Thorat AA, Dalvi S V. Liquid antisolvent precipitation and stabilization of nanoparticles of poorly water soluble drugs in aqueous suspensions: Recent developments and future perspective. Chem Eng J. 2012;181-182:1-34.

4. Duan H, Wang D, Li Y. Green chemistry for nanoparticle synthesis. Chem Soc Rev. 2015;44(16):5778-5792.

5. Arslan SA, Tirnaksiz F. A nonsteroidal antiinflammatory drug: Aceclofenac. Fabad J Pharm Sci. 2010;35(2):105-118.

6. Ryu JH, Kim J Il, Kim HS, Noh GJ, Lee KT, Chung EK. Pharmacokinetic Interactions Between Pelubiprofen and Eperisone Hydrochloride: A Randomized, Open-label, Crossover Study of Healthy Korean Men. Clin Ther. 2017;39(1):138-149.clinthera.

7. Ahmed EM. Hydrogel: Preparation, characterization, and applications: A review. J Adv Res. 2015;6(2):105-121.

8. Factor SJI, Kumar PSSP, Kumar AR, et al. International Journal of Pharmaceuticals and Health care Research. Design, Formulation And In-Vitro Evaluation Of Aceclofenac Fast Disintegrating Tablets Using Natural Polymers. 2019;07(01):23-34.

9. B. S. G. Prasad, V.R.M Gupta, Devanna N, Rama Devi M, G. V. Vardhan Rao and N. Harish. Mixed co-solvency concept. Apromising tool to enhance solubility of poor soluble drug aceclofenac. International Journal Of Pharmaceutical, Chemical And Biological Sciences Ijpcbs 2012, 2(3), 338-342

10. Gajanan V.P., Ram S.P., M.A. Saleem, R.V. Sugave, A.V. Moholkar and M.S. Digge, Enhancement of solubility of aceclofenac by recrystalization method using polar solvent, world journal of pharmaceutical research . 2015, volume 4, issue 5, 2148-2165.

11. Maulvi FA, Dalwadi SJ, Thakkar VT, Soni TG, Gohel MC, Gandhi TR. Improvement of dissolution rate of aceclofenac by solid dispersion technique. Powder Technol. 2011;207(1-3):47-54.

12. Fatimah M.H.W., Ahmed N.A. and Hayder K.A., Preparation and evaluation of ketoprofen nanoparticles. Journal of chemical and pharmaceutical research, 2017,9(12):77-87

13. Jorwekar P, Phatak A, Chaudhari P. Formulation Development of Aceclofenac Loaded Nanosupension by Three Square (3 2) Factorial Design. Int J Pharm Sci Nanotechmology. 2012;4(4):1575-1582.

14. Patel D, Dasgupta S, Dey S, Roja Ramani Y, Ray S, Mazumder B. Nanostructured lipid carriers (NLC)-based gel for the topical 
delivery of aceclofenac: Preparation, characterization, and in vivo evaluation. Sci Pharm. 2012;80(3):749-764.

15. Soni $T$, Nagda $C$, Gandhi $T$, Chotai NP. Development of discriminating method for dissolution of aceclofenac marketed formulations. Dissolution Technol. 2008;15(2):31-35.

16. Malamatari $\mathrm{M}$, Somavarapu $\mathrm{S}$, Taylor $\mathrm{KMG}$, Buckton G. Solidification of nanosuspensions for the production of solid oral dosage forms and inhalable dry powders. Expert Opin Drug Deliv. 2016;13(3):435-450.

17. Pattnaik S, Swain K, Rao JV, Varun T, Prusty KB, Subudhi SK. Aceclofenac nanocrystals for improved dissolution: Influence of polymeric stabilizers. RSC Adv. 2015;5(112):9196091965.

18. Kishore N, Dhanalekshmi UM, Raja MD, Bhavani S, Reddy PN. Design and In Vitro Evaluation of Solid-Lipid Nanoparticle Drug Delivery for Aceclofenac. J Dispers Sci Technol. 2012;33(1):96-102.

19. Jana S, Sen KK. Chitosan — Locust bean gum interpenetrating polymeric network nanocomposites for delivery of aceclofenac. Int J Biol Macromol. 2017;102:878-884.

20. Aman RM, Abu Hashim II, Meshali MM. Novel chitosan-based solid-lipid nanoparticles to enhance the bio-residence of the miraculous phytochemical “Apocynin.” Eur J Pharm Sci. 2018;124(September):304-318.

21. Gao L, Zhang D, Chen M. Drug nanocrystals for the formulation of poorly soluble drugs and its application as a potential drug delivery system. J Nanoparticle Res. 2008;10(5):845862.

22. Sethuraman N, Shanmuganathan $S$, Sandhya K, Anbarasan B. Design, development and characterization of nano structured lipid carrier for topical delivery of aceclofenac. Indian $\mathbf{J}$ Pharm Educ Res. 2018;52(4):581-586.

23. Jana S, Manna S, Nayak AK, Sen KK, Basu SK. Carbopol gel containing chitosan-egg albumin nanoparticles for transdermal aceclofenac delivery. Colloids Surfaces B Biointerfaces. 2014;114:36-44.

24. Umadevi SK, Ravi P, Rao Kusumanchi RM, Muthuprasanna P, Lakshmi PK. The effects of polymers and permeation enhancers on in vitro release of aceclofenac from topical gel formulations. Biosci Biotechnol Res Asia. 2008;5(1):237-244.

25. Singh V, Chaubey N. Design and evaluation of topical hydrogel formulation of aceclofenac for improved therapy, Journal of drug delivery and theraputics. 2019; 9(5):118-122.

26. P. Batheja, L. Sheihet , J. Kohn, A. J. Singer, B. Michniak-Kohn. Topical drug delivery by a polymeric nanosphere gel: Formulation optimization and in vitro and in vivo skin distribution studies. Journal of controlled release 149(2011) 159-167

27. Topical and Transdermal Drug Products. Pharmacopeial Forum Vol. 35(3) [May-June 2009

28. Zhang Y, Huo M, Zhou J, et al. DDSolver: An add-in program for modeling and comparison of drug dissolution profiles. AAPS J. 2010;12(3):263-271.

29. Samaha D, Shehayeb R, Kyriacos S. Modeling and comparison of dissolution profiles of diltiazem modified-release formulations. Dissolution Technol. 2009;16(2):41-46.

30. Guleri TK. Formulation and Evaluation of Topical Gel of Aceclofenac. J Drug Deliv Ther. 2013;3(6):51-53.

31. Anil K, Dilip A, Mahaveer PK, Shankar LS, Surya PS. Design development and evaluation of water dispersable tablet of aceclofenac using synthetic superdisintigrants, Asian Journal of pharmaceutical research and development, 2015:1-8

32. Thiyagarajan A, Thangarasu V. Preparation and Physicochemical Characterization of Solid Dispersion of Aceclofenac Formulated. 2011;8(1):219-224.

33. 33. Srujani. Ch, Sravanthi. B, Madhuri. D. Validated UV Spectrophotometric Methods for the Estimation of Aceclofenac in Bulk and Pharmaceutical Formulation. Sch. Acad. J. Pharm., 2014; 3(6): 471-476.

34. Girish C. Soni, PD Chaudhary, PK Sharma. Solubility Enhancement of Poorly Water Soluble Drug Aceclofenac. Indian Journal of Pharmacy and Pharmacology, 2016;3(3);139145

35. Maheshwari RK, Indurkhya A. Formulation and evaluation of aceclofenac injection made by mixed hydrotropic solubilization technique. Iran J Pharm Res. 2010;9(3):233-242.

36. Lakshmi P, Kumar GA. Nanosuspension technology: A review. Int J Pharm Pharm Sci. 2010;2(SUPPL. 4):35-40.

37. . TC, . DS, . N, . DS. A Review on Nanosuspensionspromising Drug Delivery Strategy. J Curr Pharma Res. 2012;3(1):764776.

38. Keck CM, Müller RH. Drug nanocrystals of poorly soluble drugs produced by high pressure homogenisation. Eur J Pharm Biopharm. 2006;62(1):3-16.

39. Li X, Xie S, Pan Y, et al. Preparation, characterization and pharmacokinetics of doxycycline hydrochloride and florfenicol polyvinylpyrroliddone microparticle entrapped with hydroxypropyl- $\beta$-cyclodextrin inclusion complexes suspension. Colloids Surfaces B Biointerfaces. 2016;141(February):634-642. 


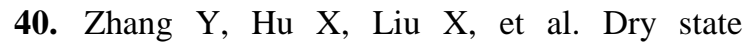
microcrystals stabilized by an HPMC film to improve the bioavailability of andrographolide. Int J Pharm. 2015;493(1-2):214-223.

41. Van De Ven H, Paulussen C, Feijens PB, et al. PLGA nanoparticles and nanosuspensions with amphotericin B: Potent in vitro and in vivo alternatives to Fungizone and AmBisome. J Control Release. 2012;161(3):795-803.

42. Ghosh I, Schenck D, Bose S, Ruegger C. Optimization of formulation and process parameters for the production of nanosuspension by wet media milling technique: Effect of Vitamin e TPGS and nanocrystal particle size on oral absorption. Eur J Pharm Sci [Internet]. 2012;47(4):718-28.

43. Li X, Gu L, Xu Y, Wang Y. Preparation of fenofibrate nanosuspension and study of its pharmacokinetic behavior in rats. Drug Dev Ind Pharm. 2009;35(7):827-833.

44. M. Snehalatha, K Venugopal \& Ranendra N. Saha. Etoposide-Loaded PLGA and PCL Nanoparticles I: Preparation and Effect of Formulation Variables. Drug Delivery, 15:5, 267-275

45. Katara R, Majumdar DK. Eudragit RL 100based nanoparticulate system of aceclofenac for ocular delivery. Colloids Surfaces B Biointerfaces. 2013;103:455-462.

46. Abdelbary AA, Li X, El-Nabarawi M, Elassasy A, Jasti B. Effect of fixed aqueous layer thickness of polymeric stabilizers on zeta potential and stability of aripiprazole nanosuspensions. Pharm Dev Technol. 2013;18(3):730-735.

47. Jawahar N, Nainar Meyyanathan S, Senthil V, Gowthamarajan K, Elango K. Studies on physico-chemical and pharmacokinetic properties of olanzapine through nanosuspension. J Pharm Sci Res. 2013;5(10):196-202.

48. J.S.Choi, J.S.Park. Design of PVP/VAS-630 based tadalafil solid dispersion to enhance the dissolusion rate. European journal of pharmaceutical sciences.S09280987(16)30523-1.

49. Vadher AH, Parikh JR, Parikh RH, Solanki AB. Preparation and characterization of co-grinded mixtures of aceclofenac and neusilin US2 for dissolution enhancement of aceclofenac. AAPS PharmSciTech. 2009;10(2):606-614.

50. Tran PHL, Tran TTD, Lee BJ. Enhanced solubility and modified release of poorly watersoluble drugs via self-assembled gelatin-oleic acid nanoparticles. Int J Pharm. 2013;455(12):235-240.

51. Prakash K, Narendra C. Development of nano particle encapsulated pemulen gel for aceclofenac topical delivery. African J Pharm Pharmacol. 2016;10(40):854-864.

52. Misal G, Dixit G, Gulkari V. Formulation and evaluation of herbal gel. Indian J Nat Prod Resour. 2012;3(4):501-505.

53. D. J Mastropietro, R. Nimroozi and $H$. Omidian. Rheology in Pharmaceutical Formulations-A Perspective, J Develop Drugs 2013, 2:2

54. Wei S, Xie J, Luo Y, et al. Hyaluronic acid based nanocrystals hydrogels for enhanced topical delivery of drug: A case study. Carbohydr Polym. 2018;202(July):64-71.

55. Abdel-Rashid RS, Helal DA, Omar MM, El Sisi AM. Nanogel loaded with surfactant based nanovesicles for enhanced ocular delivery of acetazolamide. Int $\mathrm{J}$ Nanomedicine. 2019;14:2973-2983. 